\title{
ANALISIS PREDIKSI FINANCIAL DISTRESS DENGAN MENGGUNAKAN MODEL ALTMAN Z-SCORE PADA PERUSAHAAN RITEL TAHUN 2018-2020
}

\author{
DIAN PERTIWI ${ }^{1}$ \\ ALVIANITA GUNAWAN PUTRI² \\ 1 Universitas Yapis Papua \\ diandppertiwi@gmail.com \\ 2Politeknik Negeri Semarang \\ alvianita.gp@gmail.com
}

\begin{abstract}
The retail sector is one of the sectors affected by the covid-19 pandemic. Giant is one of the hypermarkets that has closed several outlets from 2019 to 2021 permanently closed. This is due to suboptimal financial performance and exacerbated by the impact of the covid-19 pandemic. The purpose of this study is to analyze financial distress predictions in the retail sector. This study uses a sample of retail public sector companies that run hypermarket, superstore and minimarket businesses. The research analysis technique used the original Altman Z-Score model, which was developed in 1968. This study indicates generally companies are in the "safe" zone for 2018 and 2019, except for HERO, which is in the "gray" zone. Furthermore, in 2020, several companies are still in the "safe" zone, except MIDI and RALS shifting to the "gray" zone and even HERO shifting to the "distress" zone. The implications of the results of this study provide information for retail companies to pay attention to their financial conditions so that they can determine long-term strategies to have long business sustainability.
\end{abstract}

Keywords: Financial distress, Altman Z-Score, Retail, Covid-19 pandemic

\begin{abstract}
Abstrak: Sektor ritel adalah salah satu sektor yang terdampak adanya pandemi covid-19. Giant adalah salah satu hypermarket mengalami penutupan beberapa gerai mulai tahun 2019 hingga 2021 secara permanen. Hal ini karena adanya kinerja keuangan yang tidak optimal dan diperparah oleh dampak pandemi covid-19. Tujuan penelitian ini adalah untuk melakukan analisis prediksi financial distress pada sektor ritel. Penelitian ini menggunakan sampel pada perusahaan publik sektor ritel yang menjalankan bisnis hypermarket, supermarket, maupun minimarket. Teknik analisis penelitian menggunakan model Altman Z-Score original yang dikembangkan pada tahun 1968. Hasil penelitian ini menunjukkan bahwa umumnya perusahaan-perusahaan ini berada pada zona "safe" untuk tahun 2018 dan 2019, kecuali HERO yang berada pada zona "gray". Selanjutnya pada tahun 2020, beberapa perusahaan masih berada pada zona "safe", kecuali MIDI dan RALS bergeser ke zona "gray" bahkan HERO bergeser ke zona "distress". Implikasi dari hasil penelitian ini menjadi informasi bagi perusahaan ritel agar memperhatikan kondisi keuangannya sehingga dapat menentukan strategi jangka panjang agar dapat memiliki keberlangsungan usaha yang lama.
\end{abstract}

Kata kunci. Financial distress, Altman Z-Score, Ritel, Pandemi covid-19

\section{PENDAHULUAN}

Pandemi covid-19 membawa perubahan pada aktvitas yang dijalankan sehari-hari (Dewi, 2020). Perubahan aktivitas ini memberi dampak pada berbagai sektor di Indonesia (CNN Indonesia, 2020). Tidak hanya sektor kesehatan, sektor bisnis juga terkena imbasnya (Gusman, 2020). Sektor bisnis yang paling terkena dampak pandemi covid-19 adalah hotel, tempat wisata, jasa transportasi, event organizer, mal, ritel, rumah makan, bioskop, otomotif, dan barang elektronik (Nurhakliza, 2020; Sidik, 2020). Bahkan selama pandemi ini berlangsung beberapa perusahaan mengalami financial distress (Sidik, 2020).

Financial distress memberikan sinyal pada perusahaan bahwa terjadi penurunan performa keuangan terutama pada cash flow dan kemampuan pembayaran liabilitas (Carmassi \& Alessandra, 
2014). Kondisi ini menjadi pertanda bagi perusahaan bahwa perusahaan sedang menuju kebangkrutan (Carmassi \& Alessandra, 2014). Financial distress dapat dipengaruhi oleh rasio likuiditas dan leverage (Lord et al., 2020; Oktaviani et al., 2020; Stephanie et al., 2020). Fitri \& Syamwil (2020), Lord et al. (2020), dan Oktaviani et al. (2020) menyebutkan bahwa profitabilitas memliki pengaruh terhadap kemungkinan terjadinya financial distress. Selain itu, financial distress juga dapat dipengaruhi oleh ukuran perusahaan (Stephanie et al., 2020).

Selain variabel internal perusahaan, variabel eksternal seperti makro ekonomi juga dapat mempengaruhi potensi terjadinya financial distress (Dwijayanti, 2010; Iramani, 2008). Seperti kondisi ekonomi di Indonesia yang mengalami resesi mengakibatkan beberapa perusahaan mengalami kesulitan keuangan (CNN Indonesia, 2020). Sejak setahun terakhir PT Hero Supermarket Tbk melakukan penutupan beberapa gerai Giant secara permanen (CNN Indonesia, 2021). Alasan penutupan gerai ini karena selama pandemi covid-19, operasional gerai terganggu. Untuk itu, perlu dilakukan perampingan. Perampingan gerai dilakukan sebagai bentuk menjalankan strategi jangka panjang sehingga kedepannya operasional perusahaan dapat berjalan dengan efisien (Pratama, 2021). Menurut Kieso et al. (2014), perusahaan dapat mengukur efektivitas aset yang dimiliki dalam menghasilkan pendapatan penjualan dengan menggunakan rasio aktivitas. Rasio aktivitas adalah salah satu faktor yang dapat berpengaruh terhadap financial distress (Fitri \& Syamwil, 2020).

Beberapa model telah diteliti untuk memprediksi financial distress pada perusahaan. Ullah et al. (2021) memprediksi kebangkrutan pada bank-bank yang ada di Pakistan dengan menggunakan Altman Z-Score. Hasil penelitian ini menunjukkan bahwa bank lokal memperoleh hasil yang baik sedangkan bank asing diprediksi mengalami kebangkrutan. Selain Ullah et al. (2021), Puspitasari et al. (2020) juga menggunakan model Altman Z-Score untuk memprediksi financial distress sektor perbankan di Indonesia. Kedua peneliti menggunakan model Altman Z-Score untuk memprediksi kebangkrutan karena formula yang dikembangkan cocok untuk sektor perbankan (Puspitasari et al., 2020; Ullah et al., 2021).

Hastuti (2018) melakukan analisis perbandingan beberapa model prediksi financial distress perusahaan manufaktur berdasarkan model Altman Z-Score, Springate, Grover dan Ohslon. Hasil penelitian ini menunjukkan bahwa tingkat akurasi model Altman Z-Score mencapai 83,7\%. Tanjung (2020) juga menganalisis perbandingan model Altman Z-Score, Springate, Zmijeewski dan Ohlson dalam memprediksi financial distress. Hasil penelitian ini menunjukkan bahwa model Altman Z-Score yang paling akurat dalam memprediksi financial distress. Model Altman Z-Score memprediksi kebangrutan perusahaan dengan menggunakan lima faktor. Faktor-faktor yang digunakan adalah WC/TA, RE/TA, EBIT/TA, MVE/BVD dan S/TA. Dari hasi pengujian model yang dilakukan secara berulang, tingkat keakuratan model Altman Z-Score mencapai 82\% hingga 94\% (Altman \& Hotchiks, 2006).

Salah satu bisnis di sektor ritel yang terdampak pandemi covid-19 adalah Giant (Sembiring, 2021). Giant adalah salah satu bisnis hypermarket yang dijalankan oleh HERO. Pada tahun 2019 , Giant sudah menunjukkan tanda-tanda penurunan kinerja keuangan yang ditandai dengan adanya penutupan enam gerai Giant di beberapa wilayah Indonesia (Pratama, 2021; Sidik, 2021; Sugianto, 2019). Kemudian pada tahun 2020, manajeman HERO kembali melakukan penutupan gerai Giant (CNN Indonesia, 2021). Sampai pada akhirnya, manajemen HERO mengumumkan untuk menutup seluruh gerai Giant secara permanen per Juli 2020 (Sidik, 2021).

Penelitian ini bertujuan untuk melakukan analisis prediksi financial distress pada sektor ritel dengan menggunakan model Altman Z-Score. Sektor ritel dipilih karena merupakan salah satu sektor yang paling terdampak adanya pandemi covid-19. Terlebih lagi adanya penutupan beberapa gerai Giant, yang termasuk pada sektor ritel, secara permanen selama masa pandemi covid-19. Hasil penelitian ini diharapkan dapat digunakan oleh perusahaan-perusahaan dalam membangun strategi sebelum terjadinya financial distress. 


\section{Financial Distress}

Financial distress dan kebangrutan adalah istilah yang digunakan untuk menandakan bahwa performa keuangan suatu perusahaan sedang buruk. Financial distress terjadi ketika perusahaan dihadapkan pada dua masalah. Pertama, perusahaan mengalami kekurangan kas. Kedua, total liabilitas lebih besar dari total aset sehingga perusahaan mengalami kesulitan dalam melunasi kewajibannya. Kebangkrutan menunjukkan masalah yang lebih serius dibandingkan financial distress. Kebangkrutan dapat menyebabkan kepemilikan perusahaan berpindah tangan dari investor ke kreditor, dan kreditor menjadi pemegang saham yang baru atau dengan kata lain kreditor menjadi pemilik perusahaan (Carmassi \& Alessandra, 2014).

Financial distress dapat dialami oleh semua perusahaan (Dwijayanti, 2010). Apalagi jika kondisi makroekonomi suatu negara terganggu maka hal ini juga dapat memicu terjadinya financial distress pada perusahaan-perusahaan di negara tersebut (Dwijayanti, 2010; Iramani, 2008). Selain kondisi makroekonomi, financial distress juga dapat dipengaruhi oleh faktor-faktor sebagai berikut.

1. Likuiditas (Oktaviani et al., 2020; Septiani \& Dana, 2019; Stephanie et al., 2020)

2. Leverage (Fitri \& Syamwil, 2020; Oktaviani et al., 2020; Stephanie et al., 2020)

3. Provitiabilitas (Fitri \& Syamwil, 2020; Oktaviani et al., 2020)

4. Aktivitas (Ardian et al., 2017; Fitri \& Syamwil, 2020)

5. Ukuran Perusahaan (Fitri \& Syamwil, 2020; Stephanie et al., 2020)

6. Corporate Governance (Bodroastuti, 2009)

\section{Altman Z-Score}

Altman Z-Score merupakan model perhitungan yang digunakan untuk memprediksi terjadinya financial distress pada suatu perusahaan. Model ini pertama kali dikembangkan oleh Altman pada tahun 1968 (Altman \& Hotchiks, 2006). Altman (1968) mengembangan model ini menggunakan teknik statistik multiple discriminant analysis (MDA). Teknik statistik MDA ini mempertimbangkan keseluruhan profil karakteristik umum pada perusahaan yang relevan. Sedangkan teknik univariat hanya mempertimbangkan pengukuran pada perusahaan yang digunakan satu per satu (Altman, 1968). Adapun model rasio diskriminan yang telah dikembangkan pada tahun 1968 adalah sebagai berikut.

\section{Dimana}

$$
\mathrm{Z}=1.2 \mathrm{X}_{1}+1.4 \mathrm{X}_{2}+3.3 \mathrm{X}_{3}+0.6 \mathrm{X}_{4}+1.0 \mathrm{X}_{5} \ldots . .(1)
$$

$\mathrm{X}_{1}=$ Working Capital/Total Assets

$\mathrm{X}_{2}=$ Retained Earnings/Total Assets

$\mathrm{X}_{3}=$ Earnings Before Interest and Taxes/Total Assets

$\mathrm{X}_{4}=$ Market Value Equity/Total Liability

$X_{5}=$ Sales/Total Assets

$Z=$ Overall Indeks

\section{$\mathrm{X}_{1}$ - Working Capital/Total Assets}

Rasio $\mathrm{X}_{1}$ adalah pengukuran likuiditas aset neto perusahaan relatif terhadap total kapitalisasi. Modal kerja adalah selisih antara aset lancar dengan liabilitas jangka pendek. Pada rasio ini, likuiditas dan karakteristik ukuran secara eksplisit dipertimbangkan. Pada umumnya, perusahaan yang mengalami kerugian operasional terus-menerus akan memiliki aset lancar yang menyusut terhadap total aset. Rasio $\mathrm{X}_{1}$ ini terbukti paling mencerminkan keadaan perusahaan dari tiga rasio likuiditas yang telah dievaluasi (Altman, 1968; Altman \& Hotchiks, 2006).

\section{$\mathrm{X}_{2}$ - Retained Earnings/Total Assets}

Rasio $\mathrm{X}_{2}$ adalah rasio profitabilitas yang mempertimbangkan usia perusahaan secara implisit dalam pengukurannya. Perusahaan yang masih relatif muda akan menunjukkan rasio RE/TA yang rendah karena keuntungan kumulatif yang masih relatif kecil. Dengan demikian, peluangnya untuk 
diklasifikasikan sebagai perusahaan yang bangkrut relatif lebih tinggi daripada perusahaan lain yang lebih tua. Namun, rasio ini secara real menunjukkan keadaan sebenarnya dimana kegagalan banyak terjadi di tahun-tahun awal perusahaan (Altman, 1968; Altman \& Hotchiks, 2006).

\section{$X_{3}$ - Earnings Before Interest and Taxes/Total Assets}

Rasio ini adalah rasio yang menunjukkan produktivitas sebenarnya dari aset yang dimiliki perusahaan untuk menghasilkan pendapatan. Rasio $X_{3}$ sangat sesuai digunakan untuk melakukan analisis mengenai kegagalan perusahaan (Altman, 1968; Altman \& Hotchiks, 2006).

\section{$\mathrm{X}_{4}$ - Market Value Equity/Total Liability}

Nilai ekuitas diperoleh dengan menjumlahkan seluruh nilai pasar saham, baik saham preferen maupun saham biasa. Sedangkan nilai liabilitas diperoleh dengan menjumlahkan nilai liabilitas jangka pendek dan jangka panjang. Ukuran tersebut menunjukkan berapa banyak nilai aset perusahaan dapat turun sebelum total liabilitas melebihi nilai aset dan perusahaan menjadi bangkrut. Dibandingkan dengan rasio serupa yang biasa digunakan, rasio $\mathrm{X}_{4}$ adalah rasio yang paling efektif untuk mendekteksi financial distress (Altman, 1968; Altman \& Hotchiks, 2006).

\section{$X_{5}$ - Sales / Total Assets}

Rasio $\mathrm{X}_{5}$ merupakan rasio perputaran modal yang dapat mengukur kemampuan perusahaan menghasilkan pendapatan penjualan dari aset yang dimiliki oleh perusahaan. Rasio ini cukup penting karena memiliki kontribusi dalam membangun model rasio diskriminan (Altman, 1968; Altman \& Hotchiks, 2006).

Selanjutnya, Altman (1968) juga menjelaskan bahwa Z-Score dari perusahaan-perusahaan yang diteliti diklasifikasikan dalam 3 zona. Apabila hasil perhitungan Z-Score perusahaan lebih besar dari 2,99, maka perusahaan akan diklasifikasikan pada "safe zone". Sedangkan apabila hasil perhitungan Z-Score dibawah 1.81, maka akan diklasifikasikan pada "distress zone". Kemudian apabila Z-Score diantara 1,81 dan 2,99, maka akan diklasifikasikan pada "gray area" (Altman et al., 2019). Tingkat keakuratan rasio diskriminan ini mencapai 94 - 95\% sehingga terbukti keakuratannya dalam memprediksi kebangkrutan perusahaan. Dalam mengembangkan model rasio diskriminan ini, Altman (1968) menggunakan perusahaan publik pada sektor manufaktur sebagai sampel.

Model Altman Z-Score selanjutnya diperbarui. Model ini dapat digunakan untuk memprediksi financial distress bagi perusahaan privat. Adapun model Altman Z-Score ini ditandai dengan simbol Z' (Altman \& Hotchiks, 2006).

Dimana

$$
Z^{\prime}=0.717 X_{1}+0.847 X_{2}+3.107 X_{3}+0.420 X_{4}+0.998 X_{5} \ldots . .(2)
$$

$\mathrm{X}_{1}=$ Working Capital/Total Assets

$\mathrm{X}_{2}=$ Retained Earnings/Total Assets

$X_{3}=$ Earnings Before Interest and Taxes/Total Assets

$\mathrm{X}_{4}=$ Book Value of Equity/Total Liability

$X_{5}=$ Sales $/$ Total Assets

$Z=$ Overall Indeks

Perbedaan model original dan model untuk perusahaan privat ini terletak pada rasio X4 yang mana pada model tersebut menggunakan rasio nilai buku ekuitas terhadap total ekuitas. Adapun indeks klasifikasi berdasarkan skor yang diperoleh, dimana apabila Z'-Score lebih dari 2,90 maka perusahaan berada pada zona "safe", apabila Z'-Score kurang dari 1,23 maka perusahaan berada pada zona "distress", dan apabila Z'-Score diantara 1,23 sampai 2,90 maka perusahaan berada pada zona "gray" (Altman \& Hotchiks, 2006).

Modifikasi model selanjutnya dibuat dengan menghilangkan $X_{5}-$ penjualan/total aset. Rasio ini dihilangkan dengan alasan untuk meminimalkan efek dari sektor industri yang sensitif dengan rasio ini. 
Kemudian, koefisien atau berat pembobotan pada model ini juga berbeda dengan model original. Model ini dikenal dengan Emerging Market (EM) Score dan ditandai dengan simbol Z"'-Score. Model ini diklasifikasikan berdasarkan Bond Rating Equivalent (Altman, 2005; Altman \& Hotchiks, 2006).

Dimana

$$
Z^{\prime \prime}=3.25+6.56 X_{1}+3.26 X_{2}+6.72 X_{3}+1.05 X_{4} \ldots . .(3)
$$

$\mathrm{X}_{1}=$ Working Capital / Total Assets

$\mathrm{X}_{2}=$ Retained Earnings / Total Assets

$\mathrm{X}_{3}=$ Earnings Before Interest and Taxes / Total Assets

$\mathrm{X}_{4}=$ Book Value of Equity / Total Liability

$\mathrm{Z}=$ Overall Indeks

\section{METODE PENELITIAN \\ Jenis Penelitian}

Penelitian ini merupakan penelitian kuantitatif dengan analisis deskriptif. Penelitian kuantitatif deskriptif digunakan karena sesuai dengan tujuan penelitian yang akan memberikan deskripsi atau gambaran prediksi financial distress pada perusahaan publik sektor ritel.

\section{Populasi dan Sampel}

Populasi dalam penelitian ini adalah seluruh perusahaan yang terdaftar pada Bursa Efek Indonesia pada sektor ritel. Sampel dipilih dengan menggunakan teknik purposive sampling. Adapun kriteria yang ditetapkan untuk pemilihan sampel adalah sebagai berikut.

1. Perusahaan sektor ritel yang menjalankan bisnis hypermarket, supermarket, ataupun minimarket.

2. Perusahaan menerbitkan laporan keuangan untuk tahun $2018-2020$.

Berdasarkan kriteria yang telah ditetapkan, maka adapun sampel dalam penelitian ini adalah sebagai berikut.

Tabel 1 Sampel Penelitian

\begin{tabular}{lll}
\multicolumn{1}{c}{ Nama Perusahaan } & \multicolumn{1}{c}{ Kode } & \\
\hline PT Sumber Alfaria Trijaya Tbk. & AMRT & Alfamart \\
Hero Supermarket Tbk & HERO & Hero, Giant \\
Midi Utama Indonesia Tbk & MIDI & Alfa Midi \\
Matahari Putra Prima Tbk & MPPA & Hypermart, Foodmart, Smart Club \\
Ramayana Lestari Sentosa Tbk & RALS & Robinson \\
Supra Boga Lestari Tbk & RANC & Ranch Market, Farmers Market \\
\hline
\end{tabular}

Sumber: Data Diolah (2021)

Jenis Data dan Metode Pengumpulan Data

Jenis data yang digunakan dalam penelitian ini adalah data sekunder. Data yang diperlukan dalam penelitian ini adalah laporan keuangan perusahaan publik sektor ritel yang menjalankan bisnis hypermarket, supermarket, maupun minimarket. Laporan keuangan diperoleh melalui situs resmi Bursa Efek Indonesia yaitu www.idx.co.id.

\section{Variabel dan Definisi Operasional}

Variabel independen dalam penelitian ini adalah rasio-rasio yang digunakan dalam model rasio diskriminan pada Altman Z-Score. Rasio-rasio tersebut adalah WC/TA (X1), RE/TA (X2), EBIT/TA (X3), MVE/TL (X4), dan S/TA (X5). Adapun definisi operasional dari variabel independen adalah sebagai berikut. 
1. WC/TA (X1)

WC/TA adalah rasio yang digunakan untuk mengukur likuiditas perusahaan dengan cara membagi modal kerja dengan total aset.

2. $\mathrm{RE} / \mathrm{TA}(\mathrm{X} 2)$

$\mathrm{RE} / \mathrm{TA}$ adalah rasio yang digunakan untuk mengukur profitabilitas perusahaan dengan cara membagi saldo laba dengan total aset.

3. $\mathrm{EBIT/TA}(\mathrm{X} 3)$

EBIT/TA adalah rasio yang digunakan untuk mengukur produktivitas perusahaan dengan cara membagi saldo sebelum bunga dan pajak dengan total aset.

4. MVE/TL (X4)

MVE/TL adalah rasio yang digunakan untuk mengukur berapa banyak nilai aset perusahaan dapat turun sebelum total kewajiban melebihi nilai aset dan perusahaan menjadi bangkrut dengan cara membagi nilai pasar ekuitas dengan nilai buku utang.

5. S/TA (X5)

S/TA adalah rasio yang digunakan untuk mengukur aktivitas atau kemampuan perusahaan menghasilkan penjualan dari aset perusahaan dengan cara membagi penjualan dengan total aset.

Selanjutnya variabel dependen dalam penelitian ini adalah prediksi financial distress perusahaan publik sektor ritel yang menjalankan bisnis hypermarket, supermarket, maupun minimarket. Prediksi financial distress adalah indeks yang diperoleh dari hasil perhitungan Z-Score pada model rasio diskriminan Altman Z-Score.

Tabel 2 Variabel dan Definisi Variabel

\begin{tabular}{clc}
\hline Variabel & \multicolumn{1}{c}{ Definisi } & Faktor Pembobotan \\
\hline X1 & Modal kerja / Total aset & 1.2 \\
X2 & Saldo laba / Total aset & 1.4 \\
X3 & EBIT / Total aset & 3.3 \\
X4 & Nilai pasar ekuitas / Total liabilitas & 0.6 \\
X5 & Penjualan / Total aset & 1.0 \\
Z & $Z=1.2 X_{1}+1.4 X_{2}+3.3 X_{3}+0.6 X_{4}+1.0 X_{5} \ldots . .(4)$ & \\
\hline
\end{tabular}

Sumber: Altman \& Hotchiks (2006)

\section{Teknik Analisis Data}

Teknik analisis data yang digunakan dalam penelitian ini menggunakan model rasio diskriminan Altman Z-Score. Model ini digunakan untuk dapat mencapai tujuan penelitian yaitu memberikan deskripsi terkait prediksi financial distress pada perusahaan publik sektor ritel. Adapun model prediksi yang digunakan dalam penelitian ini adalah model yang dikembangkan oleh Altman pada tahun 1968, yang mana model ini merupakan model original. Dari beberapa penelitian terdahulu, model ini dapat digunakan untuk memprediksi perusahaan publik dengan tingkat keakuratan 82\% - 95\% (Altman, 1968; Altman \& Hotchiks, 2006; Hastuti, 2018; Tanjung, 2020; Ullah et al., 2021). Tahap-tahap yang dilakukan dalam menganalisis data adalah sebagai berikut.

1. Menghitung rasio-rasio yang digunakan dalam model rasio diskriminan Altman Z-Score. Perhitungan rasio-rasio ini menggunakan rumus yang telah disajikan dalam Tabel 2.

2. Menghitung Z-Score sesuai dengan formula pada model diskriminan Altman Z-Score.

Keterangan:

$$
Z S \text { core }=1.2 X_{1}+1.4 X_{2}+3.3 X_{3}+0.6 X_{4}+1.0 X_{5} \ldots . .(5)
$$

$X_{1}=$ Modal kerja terhadap total aset

$\mathrm{X}_{2}=$ Saldo laba terhadap total aset

$\mathrm{X}_{3}=\mathrm{EBIT}$ terhadap total aset 
$X_{4}=$ Nilai pasar ekuitas terhadap total liabilitas

$X_{5}=$ Penjualan terhadap total aset

$Z=$ Overall indeks

3. Mengklasifikasikan zona perusahaan sesuai indeks Z-Score yang diperoleh.

Altman (1968) mengklasifikasikan 3 zona untuk memprediksi financial distress berdasarkan skor yang telah diperoleh. Apabila skor $>2,99$ maka perusahaan berada pada zona "safe"; bila skor $>1,81$ maka perusahaan berada pada zona "distress"; dan bila skor diantara 1,81 sampai 2,99 maka perusahaan berada pada zona "gray".

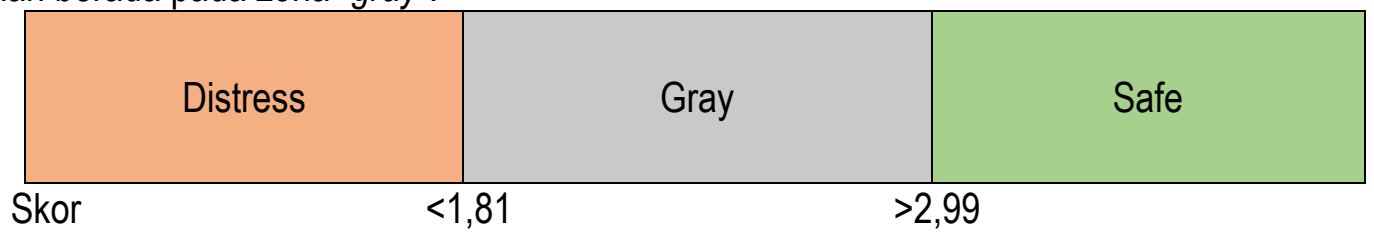

Gambar 1 Klasifikasi Zona Financial distress

\section{HASIL DAN PEMBAHASAN}

\section{Hasil Perhitungan Rasio Diskriminan}

1. WC / TA (X1)

Berikut adalah hasil perhitungan modal kerja terhadap total aset pada perusahaan publik sektor ritel yang menjalankan bisnis hypermarket, supermarket, maupun minimarket untuk tahun 2018-2020.

\begin{tabular}{lccc}
\multicolumn{4}{l}{ Tabel 4 Hasil Perhitungan WC / TA (X1) } \\
\hline Kode & 2018 & 2019 & 2020 \\
\hline AMRT & 0.08 & 0.07 & -0.07 \\
HERO & 0.13 & 0.03 & -0.15 \\
MIDI & -0.16 & -0.13 & -0.20 \\
MPPA & -0.09 & -0.19 & -0.27 \\
RALS & 0.47 & 0.51 & 0.43 \\
RANC & 0.22 & 0.23 & 0.09 \\
\hline
\end{tabular}

Sumber: Data diolah (2021)

Dari hasil perhitungan tersebut menunjukkan bahwa pada tahun 2020 rasio WC / TA semua perusahaan publik sektor ritel yang menjalankan bisnis hypermarket, supermarket, maupun minimarket mengalami penurunan dari tahun sebelumnya. Begitu pula tren pada tahun 2018 dan 2019, kecuali perusahaan MIDI, RALS, dan RANC mengalami sedikit kenaikan.

2. $\mathrm{RE} / \mathrm{TA}(\mathrm{X} 2)$

Berikut adalah hasil perhitungan saldo laba terhadap total aset pada perusahaan publik sektor ritel yang menjalankan bisnis hypermarket, supermarket, maupun minimarket untuk tahun 2018-2020.

\begin{tabular}{lccc}
\multicolumn{4}{l}{ Tabel 5 Hasil Perhitungan RE / TA $(\mathrm{X} 2)$} \\
\hline Kode & 2018 & 2019 & 2020 \\
\hline AMRT & 0.14 & 0.17 & 0.17 \\
HERO & 0.11 & 0.07 & -0.29 \\
MIDI & 0.14 & 0.17 & 0.16 \\
MPPA & -0.15 & -0.35 & -0.38 \\
RALS & 0.70 & 0.70 & 0.66 \\
RANC & 0.25 & 0.28 & 0.20
\end{tabular}

Sumber: Data diolah (2021) 
Dari hasil perhitungan tersebut menunjukkan bahwa pada tahun 2020 rasio RE / TA semua perusahaan publik sektor ritel yang menjalankan bisnis hypermarket, supermarket, maupun minimarket mengalami penurunan dari tahun sebelumnya, kecuali untuk AMRT cenderung stagnan. Untuk tren tahun 2018 ke tahun 2019, perusahaan-perusahaan ini mengalami kenaikan, kecuali HERO dan MPPA yang mengalami penurunan, serta RALS yang cenderung stagnan.

3. $\mathrm{EBIT} / \mathrm{TA}(\mathrm{X} 3)$

Berikut adalah hasil perhitungan laba sebelum beban bunga dan pajak terhadap total aset pada perusahaan publik sektor ritel yang menjalankan bisnis hypermarket, supermarket, maupun minimarket untuk tahun 2018-2020.

\begin{tabular}{lccc}
\multicolumn{4}{l}{ Tabel 6 Hasil Perhitungan EBIT / TA (X3) } \\
\hline Kode & 2018 & 2019 & 2020 \\
\hline AMRT & 0.06 & 0.08 & 0.07 \\
HERO & -0.20 & -0.01 & -0.19 \\
MIDI & 0.08 & 0.09 & 0.08 \\
MPPA & -0.19 & -0.05 & -0.03 \\
RALS & 0.14 & 0.13 & -0.03 \\
RANC & 0.07 & 0.07 & 0.06 \\
\hline
\end{tabular}

Sumber: Data diolah (2021)

Dari hasil perhitungan tersebut menunjukkan bahwa pada tahun 2020 rasio EBIT / TA semua perusahaan publik sektor ritel yang menjalankan bisnis hypermarket, supermarket, maupun minimarket mengalami penurunan dari tahun sebelumnya, kecuali untuk MPPA mengalami sedikit kenaikan. Untuk tren tahun 2018 ke tahun 2019, perusahaan-perusahaan ini mengalami kenaikan, kecuali RALS yang mengalami sedikit penurunan, dan RANC yang cenderung stagnan.

4. MVE / TL (X4)

Berikut adalah hasil perhitungan nilai pasar ekuitas terhadap total liabilitas pada perusahaan publik sektor ritel yang menjalankan bisnis hypermarket, supermarket, maupun minimarket untuk tahun 2018-2020.

\begin{tabular}{lccc}
\multicolumn{4}{l}{ Tabel 7 Hasil Perhitungan MVE $/$ TL $(\mathrm{X} 4)$} \\
\hline Kode & 2018 & 2019 & 2020 \\
\hline AMRT & 0.42 & 0.47 & 0.55 \\
HERO & 0.71 & 0.64 & 0.86 \\
MIDI & 1.26 & 1.14 & 0.82 \\
MPPA & 3.20 & 3.12 & 5.47 \\
RALS & 0.14 & 0.20 & 0.29 \\
RANC & 0.81 & 0.77 & 1.14
\end{tabular}

Sumber: Data diolah (2021)

Dari hasil perhitungan tersebut menunjukkan bahwa pada tahun 2020 rasio MVE / TL semua perusahaan publik sektor ritel yang menjalankan bisnis hypermarket, supermarket, maupun minimarket mengalami kenaikan dari tahun sebelumnya, kecuali untuk MIDI mengalami penurunan. Sedangkan untuk tren tahun 2018 ke tahun 2019, perusahaan-perusahaan ini mengalami penurunan, kecuali AMRT dan RALS yang mengalami kenaikan.

5. S / TA (X5)

Berikut adalah hasil perhitungan penjualan terhadap total aset pada perusahaan publik sektor ritel yang menjalankan bisnis hypermarket, supermarket, maupun minimarket untuk tahun 2018-2020. 


\begin{tabular}{lrrr}
\multicolumn{4}{l}{ Tabel 8 Hasil Perhitungan S / TA (X5) } \\
\hline Kode & 2018 & 2019 & \multicolumn{2}{l}{2020} \\
\hline AMRT & 3.01 & 3.04 & 2.92 \\
HERO & 2.07 & 2.01 & 1.84 \\
MIDI & 2.16 & 2.33 & 2.14 \\
MPPA & 2.22 & 2.27 & 1.50 \\
RALS & 1.09 & 0.99 & 0.48 \\
RANC & 2.61 & 2.52 & 2.28 \\
\hline
\end{tabular}

Sumber: Data diolah (2021)

Dari hasil perhitungan tersebut menunjukkan bahwa pada tahun 2020 rasio S / TA semua perusahaan publik sektor ritel yang menjalankan bisnis hypermarket, supermarket, maupun minimarket mengalami penurunan dari tahun sebelumnya. Untuk tren tahun 2018 ke tahun 2019, HERO, RALS, dan RANC mengalami penurunan, sedangkan AMRT, MIDI, dan MPPA mengalami kenaikan.

\section{Hasil Perhitungan Z-Score}

Setelah rasio-rasio diskriminan dihitung, selanjutnya Z-Score dapat diperoleh dengan mengalikan koefisien atau pembobotan dalam model original Altman Z-Score. Berikut hasil perhitungan Z-Score untu perusahaan publik sektor ritel yang menjalankan bisnis hypermarket, supermarket, maupaun minimarket.

Tabel 9 Hasil Perhitungan Z-Score

\begin{tabular}{|c|c|c|c|c|c|c|}
\hline \multicolumn{7}{|c|}{ ZScore $=1.2 X_{1}+1.4 X_{2}+3.3 X_{3}+0.6 X_{4}+1.0 X_{5}$} \\
\hline \multicolumn{7}{|c|}{ 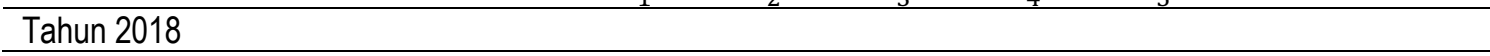 } \\
\hline Kode & $1.2 \mathrm{X} 1$ & $1.4 \mathrm{X} 2$ & $3.3 \times 3$ & $0.6 \mathrm{X} 4$ & $1.0 \times 5$ & Z \\
\hline AMRT & 0.09 & 0.20 & 0.21 & 0.25 & 3.01 & 3.76 \\
\hline HERO & 0.15 & 0.16 & -0.66 & 0.42 & 2.07 & 2.14 \\
\hline MIDI & -0.19 & 0.19 & 0.28 & 0.75 & 2.16 & 3.19 \\
\hline MPPA & -0.10 & -0.21 & -0.63 & 1.92 & 2.22 & 3.20 \\
\hline RALS & 0.56 & 0.98 & 0.47 & 0.08 & 1.09 & 3.19 \\
\hline RANC & 0.26 & 0.35 & 0.22 & 0.49 & 2.61 & 3.92 \\
\hline \multicolumn{7}{|l|}{ Tahun 2019} \\
\hline Kode & $1.2 \mathrm{X} 1$ & $1.4 \mathrm{X} 2$ & $3.3 \times 3$ & $0.6 \times 4$ & $1.0 \times 5$ & $\mathrm{Z}$ \\
\hline AMRT & 0.08 & 0.24 & 0.25 & 0.28 & 3.04 & 3.90 \\
\hline HERO & 0.03 & 0.10 & -0.02 & 0.38 & 2.01 & 2.51 \\
\hline MIDI & -0.15 & 0.23 & 0.31 & 0.68 & 2.33 & 3.40 \\
\hline MPPA & -0.22 & -0.49 & -0.16 & 1.87 & 2.27 & 3.26 \\
\hline RALS & 0.61 & 0.98 & 0.43 & 0.12 & 0.99 & 3.13 \\
\hline RANC & 0.28 & 0.39 & 0.22 & 0.46 & 2.52 & 3.87 \\
\hline \multicolumn{7}{|l|}{ Tahun 2020} \\
\hline Kode & $1.2 \times 1$ & $1.4 \mathrm{X} 2$ & $3.3 \times 3$ & $0.6 \mathrm{X} 4$ & $1.0 \times 5$ & Z \\
\hline AMRT & -0.08 & 0.24 & 0.22 & 0.33 & 2.92 & 3.63 \\
\hline HERO & -0.18 & -0.40 & -0.62 & 0.52 & 1.84 & 1.15 \\
\hline MIDI & -0.24 & 0.23 & 0.26 & 0.49 & 2.14 & 2.87 \\
\hline MPPA & -0.33 & -0.53 & -0.10 & 3.28 & 1.50 & 3.83 \\
\hline RALS & 0.52 & 0.93 & -0.09 & 0.17 & 0.48 & 2.00 \\
\hline RANC & 0.10 & 0.27 & 0.18 & 0.68 & 2.28 & 3.52 \\
\hline
\end{tabular}

Sumber: Data diolah (2021)

\section{Hasil Pengklasifikasikan Zona Financial Distress}

Berikut ini adalah hasil pengklasifikasian zona financial distress pada perusahaan publik sektor ritel yang menjalankan bisnis hypermarket, supermarket, maupun minimarket untuk tahun 2018 - 2020. 
Tabel 10 Klasifikasi Zona Financial Distress

\begin{tabular}{lcccccc}
\hline & \multicolumn{3}{c}{ Z-Score } & \multicolumn{3}{c}{ Klasifikasi Zona } \\
\cline { 2 - 7 } \multicolumn{1}{c}{ Kode } & 2018 & 2019 & 2020 & 2018 & 2019 & 2020 \\
\hline AMRT & 3.76 & 3.90 & 3.63 & Safe & Safe & Safe \\
HERO & 2.14 & 2.51 & 1.15 & Gray & Gray & Distress \\
MIDI & 3.19 & 3.40 & 2.87 & Safe & Safe & Gray \\
MPPA & 3.20 & 3.26 & 3.83 & Safe & Safe & Safe \\
RALS & 3.19 & 3.13 & 2.00 & Safe & Safe & Gray \\
RANC & 3.92 & 3.87 & 3.52 & Safe & Safe & Safe \\
\hline
\end{tabular}

Sumber: Data diolah (2021)

\section{Pembahasan}

Hasil analisis prediksi financial distress pada perusahaan publik sektor ritel yang menjalankan bisnis hypermarket, supermarket, maupun minimarket bervariasi. Pada tahun 2018 hingga tahun 2019 hasil klasifikasi zona financial distress untuk perusahaan publik sektor ritel yang menjalan bisnis hypermarket, supermarket, maupun minimarket umumnya berada pada zona "safe" atau dapat dikatakan perusahaan dalam keadaan aman. Hanya saja, HERO telah menunjukkan gejala yang menandakan adanya financial distress. Dimana pada tahun 2018 dan 2019 HERO telah menunjukkan klasifikasi di zona "gray" atau zona rawan yang seharusnya manajemen berhati-hati terhadap kondisi perusahaan saat itu.

Pada tahun 2020, beberapa perusahaan tetap bisa mempertahankan posisinya pada zona "safe". Namun, perusahaan lain menunjukkan adanya penurunan zona klasifikasi. Perusahaan publik secktor ritel yang menjalankan bisnis hipermartket, supermarket, maupun minimarket yang masih berada pada zona "safe" pada tahun 2020 adalah AMRT, MPPA, dan RANC. Sedangkan MIDI dan RALS berada pada zona "gray" dan HERO berada pada zona "distress". Hal ini menunjukkan bahwa HERO diprediksi mengalami financial distress. Dan untuk kedepannya sangat diperlukan adanya perbaikan ataupun pembaruan strategi perusahaan agar perusahaan dapat bertahan dan tidak bangkrut.

Variabel yang paling mempengaruhi jumlah Z-Score pada perusahaan publik sektor ritel yang menjalankan bisnis hypermarket, supermarket, maupun minimarket pada tahun 2018-2020 adalah X5, dimana X5 merupakan rasio aktivitas yang mengukur kemampuan perusahaan menghasilkan penjualan dari total aset yang dimiliki (Altman \& Hotchiks, 2006). Hasil analisis data menunjukkan bahwa pada tahun 2020 rasio aktivitas ini mengalami penurunan dari tahun-tahun sebelumnya. Penurunan rasio aktivitas membuat adanya penurunan Z-Score sehingga perusahaan memperoleh hasil klasifikasi zona "gray", bahkan "distress". Ini sesuai dengan penelitian (Ardian et al., 2017; Fitri \& Syamwil, 2020) yang menyimpulkan bahwa rasio aktivitas berpengaruh terhadap financial distress suatu perusahaan.

Rasio aktivitas yang mengalami penurunan mengindikasikan bahwa penjualan perusahaan publik sektor ritel yang menjalankan bisnis hypermarket, supermarket, maupun minimarket pada tahun 2020 mengalami penurunan. Penurunan penjualan dapat disebabkan karena turunnya daya beli masyarakat. Seperti yang diketahui bahwa pandemi covid-19 yang terjadi saat ini membawa dampak adanya penurunan daya beli masyarakat sehingga pada tahun 2020 perekonomian Indonesia mengalami resesi sebesar 2,19\% (BPS, 2021; Muhammad et al., 2020; Yuniati \& Amini, 2020). Hal ini sesuai dengan penelitian Dwijayanti (2010) dan Iramani (2008) menunjukkan bahwa keadaan ekonomi dapat berpengaruh terhadap financial distress perusahaan.

Selain rasio aktivitas, rasio likuiditas, yang disimbolkan dengan X1, juga mengalami penurunan yang cukup signifikan pada tahun 2020 dibandingkan dengan tahun-tahun sebelumnya. Rasio ini akan menunjukkan bahwa perusahaan yang mengalami kerugian operasi yang konsisten akan memiliki aset lancar yang menyusut terhadap total aset (Altman, 1968; Altman \& Hotchiks, 2006). Hal ini sesuai dengan 
penelitian Oktaviani et al., (2020) dan Stephanie et al. (2020) yang menyimpulkan bahwa likuiditas berpengaruh terhadap financial distress.

\section{PENUTUP}

Penelitian ini bertujuan untuk memprediksi financial distress pada perushaan publik sektor ritel yang menjalankan bisnis hypermarket, supermarket, maupun minimarket untuk tahun 2018-2020. Dari hasil analisis data dengan menggunakan model Altman Z-Score original ditemukan bahwa pada tahun 2020 HERO berada pada zona "distress". Sedangkan AMRT, MPPA, dan RANC berada pada zona "safe" serta MIDI dan RALS berada pada zona "gray". Klasifikasi zona pada tahun 2020 untuk perusahaan publik sektor ritel yang menjalankan bisnis hypermarket, supermarket, maupun minimarket mengalami penurunan peringkat dari tahun sebelumnya. Penurunan peringkat klasifikasi ini tentunya dihasilkan dari perhitungan Z-Score yang rendah. Rendahnya hasil Z-Score terutama dipengaruhi oleh X1 (rasio likuiditas) dan X5 (rasio aktivitas). Hasil yang skor yang rendah juga disebabkan adanya pengaruh keadaan makroekonomi yang terdampak pandemi covid-19.

Penelitian memiliki keterbatasan pada jumlah sampel yang sedikit dan hanya menggunakan satu model prediksi financial distress. Diharapkan untuk penelitian selanjutnya menggunakan sektor lain yang juga terdampak akibat adanya pandemi covid-19 dengan menggunakan dan membandingkan lebih dari satu model prediksi financial distress. Implikasi dari hasil penelitian ini menjadi informasi bagi perusahaan publik sektor ritel yang menjalankan bisnis hypermarket, supermarket, maupun minimarket agar memperhatikan kondisi keuangannya sehingga dapat menentukan strategi jangka panjang agar dapat memiliki keberlangsungan usaha yang lama.

\section{DAFTAR PUSTAKA}

Altman, E. I. (1968). Financial Ratios, Discriminant Analysis And The Prediction Of Corporate Bankruptcy. The Journal Of Finance, XXIII(4), 589-609.

Altman, E. I. (2005). An Emerging Market Credit Scoring System For Corporate Bonds. Emerging Market Review, 6, 311-323.

Altman, E. I., \& Hotchiks, E. (2006). Corporate Financial Distress and Bankruptcy (Third). John Wiley \& Sons, Inc. https://doi.org/10.1007/978-3-319-67355-4_2

Altman, E. I., Hotchiks, E., \& Wang, W. (2019). Corporate Financial Distress, Restructuring, and Bankruptcy (Fourth). John Wiley \& Sons, Inc.

Ardian, A. V., Andini, R., \& Raharjo, K. (2017). Pengaruh Rasio Likuiditas, Rasio Leverage, Rasio Aktivitas, dab Profitabilitas Terhadap Financial Distress. Jurnal Ilmiah Mahasiswa Akuntansi Universitas Panandaran, 3(3).

Bodroastuti, T. (2009). The Influence of Corporate Governance Structure to Financial Distress. Jurnal IImu Ekonomi ASET, 11(2), 1-15.

BPS. (2021). Pertumbuhan Ekonomi Indonesia Triwulan IV-2020. Www.Bps.Go.Id, 13, 12. https://www.bps.go.id/pressrelease/2021/02/05/1811/ekonomi-indonesia-2020-turun-sebesar-207-persen--c-to-c-.html

Carmassi, C., \& Alessandra, P. (2014). Financial Distress and Bankruptcy: Tools for preserving the Soundness of Financial System. LUISS Guido Carli. https://tesi.luiss.it/15689/1/176421.pdf

CNN Indonesia. (2020). Dampak Resesi Corona Mengalir ke Berbagai Sektor. CNN Indonesia. https://www.cnnindonesia.com/ekonomi/20200908105412-532-543899/dampak-resesi-coronamengalir-ke-berbagai-sektor

CNN Indonesia. (2021). Daftar Gerai Giant yang Tutup. CNN Indonesia. 
https://www.cnnindonesia.com/ekonomi/20210305102841-92-614067/daftar-gerai-giant-yangtutup

Dewi, R. K. (2020). Mengenal Apa Itu PSBB, Aturan, Daerah Yang Menerapkan Hingga Sanksinya. Kompas. https://www.kompas.com/tren/read/2020/04/14/093800065/mengenal-apa-itu-psbbaturan-daerah-yang-menerapkan-hingga-sanksinya?page=all

Dwijayanti, S. (2010). Penyebab, Dampak, Dan Prediksi Dari Financial Distress Serta Solusi Untuk Mengatasi Financial Distress. Jurnal Akuntansi Kontemporer, 2(2), 191-205.

Fitri, R. A., \& Syamwil, S. (2020). Pengaruh Likuiditas, Aktivitas, Profitabilitas dan Leverage Terhadap Financial Distress (Studi Kasus pada Perusahaan Manufaktur yang Terdaftar di Bursa Efek Indonesia Periode 2014-2018). Jurnal Ecogen, 3(1), 134. https://doi.org/10.24036/jmpe.v3i1.8532

Gusman, H. (2020). Enam Bulan COVID-19 Rl: Sektor Kesehatan \& Ekonomi Masih Buruk. Tirto.Id. https://tirto.id/enam-bulan-covid-19-ri-sektor-kesehatan-ekonomi-masih-buruk-f3eu

Hastuti, R. T. (2018). Analisis Komparasi Model Prediksi Financial Distress Altman, Springate, Grover Dan Ohlson Pada Perusahaan Manufaktur Yang Terdaftar Di Bursa Efek Indonesia Periode 20112013. Jurnal Ekonomi, 20(3), 446. https://doi.org/10.24912/je.v20i3.405

Iramani, R. (2008). Model Prediksi Financial Disress Perusahaan Go Public di Indonesia (Studi pada Sektor Manufaktur). Jurnal Aplikasi Manajemen, 6.

Kieso, D. E., Weygant, J. J., \& Warfield, T. D. (2014). Intermediate Accounting IFRS Edition (2nd Ed). John Wiley \& Sons, Inc.

Lord, J., Landry, A., Savage, G. T., \& Weech-Maldonado, R. (2020). Predicting Nursing Home Financial Distress Using the Altman Z-Score. Inquiry (United States), 57. https://doi.org/10.1177/0046958020934946

Muhammad, M., Aditia Mahardika, \& Rizka Amalia. (2020). Corona Virus Pandemic Impact on Sales Revenue of Micro Small and Medium Enterprises (MSMEs ) in Pekalongan City, Indonesia. Journal of Vocational Studies on Applied Research, 2(1), 7-10. https://ejournal2.undip.ac.id/index.php/ivsar/article/view/7600

Nurhakliza, S. (2020). Sembilan Sektor Paling Parah Kena Dampak, No.2 Rugi hingga USD812 Juta. Idxchannel.Com. https://www.idxchannel.com/market-news/foto/sembilan-sektor-paling-parahkena-dampak-no2-rugi-hingga-usd812-juta

Oktaviani, B., Hizai, A., \& Mirdah, A. (2020). Ukuran Perusahaan Terhadap Financial Distress Terdaftar di Bursa Efek Indonesia. Jambi Accounting Review ( JAR ), 1(April), 20-34.

Pratama, A. (2021). Bos Hero Ungkap Alasan Tutup Gerai Giant. Idxchannel.Com. https://www.idxchannel.com/market-news/bos-hero-ungkap-alasan-tutup-gerai-giant

Puspitasari, D. M., Roespinoedji, D., \& Napitupulu, S. (2020). Applicability of Altman Model in Predicting Financial Distress : Evidence from Rural Bank in Indonesia. Solid State Technology, 63(3).

Sembiring, L. J. (2021). Giant Tutup, Centro Pailit, Kapan "Mimpi Buruk" ini Berakhir? CNBC Indonesia. https://www.cnbcindonesia.com/market/20210529172959-17-249273/giant-tutup-centro-pailitkapan-mimpi-buruk-ini-berakhir

Septiani, N. M. I., \& Dana, I. M. (2019). Pengaruh Likuiditas, Leverage, Dan Kepemilikan Institusional Terhadap Financial Distress Pada Perusahaan Property Dan Real Estate. E-Jurnal Manajemen Universitas Udayana, 8(5), 3110. https://doi.org/10.24843/ejmunud.2019.v08.i05.p19

Sidik, S. (2020). Emiten dari Sektor Ini Paling Sengsara Hadapi Efek Covid-19. CNBC Indonesia. https://www.cnbcindonesia.com/market/20200512130429-17-157880/emiten-dari-sektor-ini-palingsengsara-hadapi-efek-covid-19

Sidik, S. (2021). Sayonara Gerai Giant! Ternyata Separah Ini Kinerja HERO. CNBC Indonesia. https://www.cnbcindonesia.com/market/20210525135916-17-248255/sayonara-gerai-giant- 
ternyata-separah-ini-kinerja-hero

Stephanie, Lindawati, Suyanni, Christine, Oknesta, E., \& Afiezan, A. (2020). Pengaruh Likuiditas, Leverage dan Ukuran Perusahaan Terhadap Financial Distress Pada Prusahaan Properti dan Perumahan. Costing: Journal of Economic, Business and Accounting, 3.

Sugianto, D. (2019). BEI Desak HERO Jelaskan Kabar Penutupan 6 Gerai Giant. Detik Finance. https://finance.detik.com/berita-ekonomi-bisnis/d-4598979/bei-desak-hero-jelaskan-kabarpenutupan-6-gerai-giant

Tanjung, P. R. (2020). Comparative Analysis Of Altman Z-Score, Springate, Zmijewaki and Ohlson Models ini Predicting Financial Distress. EPRA International Journal of Multidisciplinary Research (IJMR)-Peer Reviewed Journal, 6(3). https://doi.org/https://doi.org/10.36713/epra4162

Ullah, H., Wang, Z., Abbas, M. G., Zhang, F., Shahzad, U., \& Mahmood, M. R. (2021). Association of Financial Distress and Predicted Bankruptcy: The Case of Pakistani Banking Sector. Journal of Asian Finance, Economics and Business, 8(1), 573-585. https://doi.org/10.13106/jafeb.2021.vol8.no1.573

Yuniati, M., \& Amini, R. (2020). Analisis Dampak Covid-19 Terhadap Daya Beli Masyarakat Ntb. Jurnal Penelitian Manajemen, 2(2), 362-368. www.kelaspintar.id.lbkg/inspirasi/pengaruh-covid19/terhadap/-perekonomian- 